\title{
Implementation of a Cardiovascular Disease Prevention Program among School-Aged Children: A Pilot Study
}

\author{
Clifton C. Addison ${ }^{1 *}$, Brenda W. Jenkins ${ }^{1}$, Monique S. White ${ }^{1}$, and Lavon Young ${ }^{1}$ \\ ${ }^{1}$ Project Health/Jackson Heart Study, Jackson State University, 350 W. Woodrow Wilson Drive, Jackson, Mississippi, USA \\ *Correspondence to Dr. Clifton C. Addison. Email: clifton.addison@ jsums.edu
}

Received: 03 November 20052 / Accepted: 07 July 2006 / Published: 30 September 2006

\begin{abstract}
The objective of this study was to test students' knowledge of cardiovascular disease information and to determine if a carefully structured training program administered to high school students would increase their knowledge about cardiovascular disease and risk factors that are preventable. A pilot study was conducted during which fifty high school students from nine counties in the State of Mississippi were measured for their knowledge of hypertension both at baseline and after the completion of an intervention training activity. There were significant gains in knowledge between the pre-test and the post-test that the students completed. The gains in knowledge indicate that elimination of risk factors is possible if all health care and school-based prevention programs are implemented to positively impact changes in eating and physical activity behaviors. Students' involvement in such activities could translate into significant changes in risk factors at these ages and throughout their lifetime. It is widely accepted that these behavioral changes, if sustained into adulthood, could have the potential to influence cardiovascular risk reduction.
\end{abstract}

Keywords: Cardiovascular disease, prevention, students, training pre-test, post-test

\section{Introduction}

In many instances, cardiovascular disease (CVD) is lifestyle related and associated with a number of risk factors that begin the debilitating progression in childhood, particularly obesity, hypertension and smoking [1, 2]. Judging from the large number of people dying worldwide from cardiovascular diseases, it is now estimated that 25 million people will die from these diseases by 2025 , unless significant prevention efforts can halt this rise [3]. The World Health Organization (WHO) calls cardiovascular disease (CVD) one of three "neglected global epidemics" [4].

During the past half-century, many epidemiological studies have consistently documented reduction in the incidence of coronary artery disease (CAD) events in the more physically active and fit subjects [5]. Studies have demonstrated that the most sedentary individuals generally have $\mathrm{CAD}$ rates twice as often as physically active individuals. As activity levels increase, the rates of CAD tend to decrease $[6,7]$. It can be concluded, then, that physical activity reduces the incidence of CAD. Physical activity both prevents the development of disease and helps treat many established risk factors, such as elevated blood pressure, insulin resistance and glucose intolerance, elevated triglyceride concentrations, low highdensity lipoprotein cholesterol (HDL-C) concentrations, and obesity. Exercise in combination with weight reduction can decrease low-density lipoprotein cholesterol (LDL-C) concentrations and limit the reduction in HDL-C that often occurs with a reduction in dietary saturated fat [8].

The CATCH [1], CHIC [9] and Heart Smart programs [10] are all school-based cardiovascular-based intervention programs that have achieved a change in risk factors. It is increasingly recognized that individual values, beliefs and behavior operate within a social context, like the school and home environment. There is evidence of decreased perceived health risk following public health, physical and social interventions to improve health, suggesting that programs of this type should be considered by school administrators when planning school-based health promotion interventions [11].

There are various ways to present knowledge and gather information that can play an important role in the policy formation process. Consideration should always be given to these procedures because public health and health 
promotion issues should always be addressed when changing policy and considering concepts of interactive and critical knowledge in addition to scientific knowledge. The development of a meaningful health policy should involve an acceptance of these various avenues for disseminating knowledge and instituting frameworks that encourage professionals and citizens to work together to develop and achieve public health and health promotion goals [12].

The objective of this study was to implement a cardiovascular disease information intervention program for school aged students and to test the students' knowledge of basic cardiovascular disease information. The ultimate goal was to determine if a carefully structured training program administered to high school students could increase their knowledge about cardiovascular disease and provide them with effective strategies for eliminating or reducing risk factors that are preventable.

\section{Methods}

The study took the form of a prevention program aimed at examining knowledge gains of students with the intention of ultimately implementing a comprehensive prevention module. The procedures included a needs assessment, intervention, pre-test and post-test evaluation phases. Prior to the development of the prevention program, a meeting was held with staff and teachers of a local school district where all members of the staff present were surveyed for information on student practices, organization policy toward student risk behaviors, frequency of contact with the target age group and willingness to undertake health promotion activities [13]. Based on the results of this teachers' survey, it was decided to develop a prevention/intervention program incorporating information about cardiovascular disease and risk factors for developing such diseases. It was decided that prior to the development and implementation of this comprehensive health information intervention, a pilot study should be convened where students would be exposed to information about hypertension and would be given the opportunity to display their knowledge by participating in a pre-test and a post-test. This pilot study was undertaken during a weekend conference with students who were participating in a developmental program at a Mississippi college.

\section{Subjects}

The subjects for this study were 50 Upward Bound students enrolled in the Mississippi College weekend and summer workshops. The Upward Bound Math and Science program is a federally funded, pre-college enrichment program designed to generate skills and motivation in mathematics and science for success in education beyond high school. The program concentrates on young people from disadvantaged backgrounds who have an academic need and a desire to attend a post- secondary institution. The students enrolled in the program represented 10th and $11^{\text {th }}$ grade students from schools in nine counties in the State of Mississippi (Copiah, Hinds, Issaquena, Leake, Madison, Sharkey, Simpson, Washington and Yazoo counties). In addition to the academic training received, students were required to attend lectures on other issues that affect their lives, and so they were required to attend lectures and training in prevention of cardiovascular diseases where they were provided information on risk factors for chronic diseases, types of prevention behaviors and practices they could adopt for improving the quality of their lives.

Prior to the beginning of the training, students were given a pre-test to test their knowledge on issues relating to high blood pressure. After the training was completed, the students were again tested to assess whether their knowledge had changed after exposure to the new information presented as part of the prevention activities.

It was hypothesized that students, who were exposed to training about chronic disease and disease prevention, would increase their knowledge, measured by comparing changes in the results of the pre-test and the post-test.

\section{Instrument}

The students were administered a short five-item survey that asked questions about high blood pressure, the numbers used to classify high blood pressure, and what is a normal blood pressure reading. They were also asked to respond about their knowledge about one risk factor for heart disease. This survey sought to test the knowledge of this target population. The information program which served as the intervention allowed the students to actively participate in an information session during which they were provided with information and training on issues relating to high blood pressure, important measurements to help them monitor their cardiovascular health, and general cardiovascular disease prevention behaviors.

\section{Statistical Analysis}

The data were analyzed using SPSS and the students' information was reported in the form of frequencies and percentages. The paired t-test was computed to examine the students' responses for differences between the pre-test and the post-test that could be attributed to exposure to the training provided.

\section{Results}

Of the 50 students who agreed to participate in the program, 39 of them provided both pre and post tests that were usable for analysis in this study. At follow-up, most of the students showed significant gains in cardiovascular disease knowledge on the target topics covered in the curriculum (Table 1). When asked "What disease is known as the silent killer?" $87.2 \%$ of the students did not know the answer on the pre-test, whereas $94.9 \%$ of them answered correctly on the post-test. 
Table 1: Students' pre-test and post-test responses

\begin{tabular}{|c|c|c|c|}
\hline \multirow{2}{*}{ Category } & & \multicolumn{2}{|c|}{ Frequency } \\
\hline & & $\begin{array}{c}\text { Pre Test } \\
(\%)\end{array}$ & $\begin{array}{r}\text { Post Test } \\
(\%)\end{array}$ \\
\hline \multirow{2}{*}{$\begin{array}{l}\text { What disease is } \\
\text { known as 'the } \\
\text { silent killer? }\end{array}$} & $\begin{array}{l}\text { High blood } \\
\text { pressure }\end{array}$ & 12.8 & 94.9 \\
\hline & Don't know & 87.2 & 5.1 \\
\hline \multirow{2}{*}{$\begin{array}{l}\text { What is the top } \\
\text { number of blood } \\
\text { pressure called? }\end{array}$} & Systolic & 0 & 64.1 \\
\hline & Don't know & 100.0 & 36.9 \\
\hline \multirow{2}{*}{$\begin{array}{l}\text { What is the bottom } \\
\text { number of blood } \\
\text { pressure called? }\end{array}$} & Diastolic & 0 & 64.1 \\
\hline & Don't know & 100.0 & 36.9 \\
\hline \multirow{2}{*}{$\begin{array}{l}\text { What is considered } \\
\text { normal blood } \\
\text { pressure reading? }\end{array}$} & $120 / 80$ & 0 & 84.6 \\
\hline & Don't know & 100.0 & 15.4 \\
\hline \multirow{2}{*}{$\begin{array}{l}\text { Name two diseases } \\
\text { that are related to } \\
\text { the presence of } \\
\text { high blood pressure }\end{array}$} & Know & 10.3 & 87.2 \\
\hline & Don't know & 89.7 & 12.8 \\
\hline
\end{tabular}

There were $5.1 \%$ of the students who did not appear to have benefited from the intervention program, however. Students were also asked "What is the top number of blood pressure called?" None of them knew the answer to this question in the pre-test, but $64.1 \%$ of them had the correct answer on the post-test. There were $36.1 \%$ of them who did not know the answer to this question. On the question "What is the bottom number of the high blood pressure called?", again, none of them knew the answer on the pre-test, while $64.1 \%$ of them answered correctly on the post-test. There were $36.4 \%$ of them who still did not know the answer after the intervention. The students were asked "What is considered normal blood pressure reading?" None of them knew the answer to this question on the pre-test, while $84.6 \%$ of them gave the correct answer on the post-test: $15.6 \%$ of them did not have the right answer, even after being exposed to the intervention. When students were asked to "Name two diseases that are related to the presence of high blood pressure", only $10.3 \%$ of them could do so on the pre-test, while $87.2 \%$ of them had improved knowledge on the post-test. Still, $12.8 \%$ of the students did not improve from the pre-test to the posttest.

Table 2 is a presentation of the paired t-test that was computed to test for differences between the pre-test and post-test scores of the students. On the question "What disease is known as the silent killer?", significant differences were found between the pre-test scores and the post-test scores of the students $(\mathrm{p}<0.05)$. The significance level computed was $\mathrm{p}=0.000$. Knowledge increased for $82 \%$ of the students. On the question "What is the top number of blood pressure called?", significant differences were found between the pre-test scores and the post-test scores of the students $(\mathrm{p}<0.05)$. The significance level computed was $\mathrm{p}=$ 0.000 . Knowledge increased for $64 \%$ of the students. On the question "What is the bottom number of the high blood pressure called?", significant differences were found between the pre-test scores and the post-test scores of the students $(\mathrm{p}<0.05)$. The significance level computed was $\mathrm{p}=$ .000 . Knowledge increased for $64 \%$ of the students. On the question "What is considered normal blood pressure reading?" significant differences were found between the pre-test scores and the post-test scores of the students $(\mathrm{p}<$ $0.05)$. The significance level computed was $\mathrm{p}=0.000$. Knowledge increased for $85 \%$ of the students. On the question "Name two diseases that are related to the presence of high blood pressure?", significant differences were found between the pre-test scores and the post-test scores of the students $(\mathrm{p}<$ 0.05 ). The significance level computed was $p=0.000$. Knowledge increased for $77 \%$ of the students (see Table 2).

Table 2: Proportion increase in knowledge among students from pre-test to post-test

\begin{tabular}{|c|c|c|c|c|c|c|}
\hline Category & $\begin{array}{c}\text { Mean } \\
\text { Increase }\end{array}$ & $S D$ & $\begin{array}{l}95 \% \text { CI of } \\
\text { Difference }\end{array}$ & $t$ & $d f$ & Sig (2-tailed) \\
\hline \multicolumn{7}{|l|}{ What Disease is known as 'the silent killer? } \\
\hline Increase from pre-post test & .82 & .51 & $.66-.98$ & 10.119 & 38 & 0.000 \\
\hline $\begin{array}{l}\text { What is the top number of blood pressure called? } \\
\text { Increase from pre-post test }\end{array}$ & .64 & .49 & $.48-.79$ & 8.238 & 38 & 0.000 \\
\hline $\begin{array}{l}\text { What is the bottom number of the high blood } \\
\text { pressure called? } \\
\text { Increase from pre-post test }\end{array}$ & .64 & .49 & $.48-.49$ & 8.238 & 38 & 0.000 \\
\hline $\begin{array}{l}\text { What is considered normal blood pressure reading? } \\
\text { Increase from pre-post test }\end{array}$ & .85 & .37 & $.73-.96$ & 14.457 & 38 & 0.000 \\
\hline $\begin{array}{l}\text { Name two disease that are related to the presence } \\
\text { of high blood pressure } \\
\text { Increase from pre-post test }\end{array}$ & .77 & .48 & $.61-.93$ & 9.193 & 38 & 0.000 \\
\hline
\end{tabular}




\section{Conclusion}

This study demonstrated that students can become knowledgeable about health risk factors and preventive measures through guided, supervised exposure to instruction that specifically addresses health concerns. These findings support the efforts of many organizations, including the Centers for Disease Control and Prevention (CDC) that have begun to advocate the development of action plans designed to help children respond responsibly to these health concerns. These action plans must address various approaches and must incorporate information exchange with students within their academic curriculum, in order to be effective in reducing cardiovascular diseases, particularly among groups like African Americans, who suffer disproportionately from the effects of these diseases.

The data examined in this study show that adequate training could be a key element in all CVD prevention programs for prevention activities to be effective and sustainable in the long run. The exposure of the students to the information program after the pre-test and the subsequent increases in knowledge about hypertension demonstrated that health promotion could become a successful component of school policy and public policy, and specific lifestyle targets should be set for children regarding other risk factors such as smoking, diet and exercise, practices and behaviors over which they have total control. It is hoped that health promotion activity would become a compulsory part of general school activities. This study shows that it is feasible to deliver an effective prevention program by addressing students' daily negative practices in school and at home. It is also believed that the students' understanding of the association between those practices and the occurrence of negative cardiovascular outcomes could possibly lead to a reduction of such outcomes.

Acknowledgements: This study has been made possible by a grant from "The Excellence in Partnerships for Community Outreach" funded by The United States Department of Health and Human Services (Project Export). Grant Number: 5P20MD000534-02. The Study was also supported by the Community Foundation of Greater Jackson.

\section{References}

1. Webber L S.; Osganion S.; Feldman H.; Wu M.; Mckenzie T.; Nichaman M.;Lytle, L. A.; Edmundson, E.; Cutler, J.; Nader, P. R.: Cardiovascular risk factors among children after a 2 1/2 year intervention---the CATCH study. Preventive Medicine, 1996, 25, 432-441.
2. Boreham C.; Savage .J. M.; Primrose D.; Cran G.; Strain, J.: Coronary risk factors in schoolchildren. Arch Dis Child, 1993, 68 (2), 182-186.

3. Thompson, P. D.; Buchner, D.; Pina, I. L.; Balady, G. J.; Williams, M. A.; Marcus, B. H.; Berra, K.; Blair, S. N.; Costa, F.; Franklin, B.; Fletcher, G. F.; Gordon, N. F.; Pate, R.; Rodriguez, B. L.; Yancey, A.,K.; Wenger, N. K.: Exercise and physical activity in the prevention and treatment of atherosclerotic cardiovascular disease: a statement from the Council on Clinical Cardiology (Subcommittee on Exercise, Rehabilitation, and Prevention) and the Council on Nutrition, Physical Activity, and Metabolism (Subcommittee on Physical Activity). Circulation, 2003, 107(24):3109-3116.

4. Centers for Disease Control and Prevention. Chronic Disease. Chronic Disease Notes and Reports, 2004, 17[1].

5. Lee, I. M.; Paffenbarger R. S. Jr.; Hennekens, C. H.: Physical activity, physical fitness and longevity. Aging (Milano), 1997, 9(1-2):2-11.

6. Blair, S. N.; Jackson, A. S.: Physical fitness and activity as separate heart disease risk factors: a metaanalysis. Med Sci Sports Exerc, 2001, 33(5):762-764.

7. Powell K. E.; Thompson, P. D.; Caspersen, C. J.; Kendrick, J. S.: Physical activity and the incidence of coronary heart disease. Annu Rev Public Health, 1987, 8:253-287.

8. Stefanick, M. L.; Mackey, S.; Sheehan, M.; Ellsworth N.; Haskell, W. L.; Wood, P. D.: Effects of diet and exercise in men and postmenopausal women with low levels of HDL cholesterol and high levels of LDL cholesterol. N. Engl J Med, 1998, 339(1):12-20.

9. Harrell, J.; McMurray, R.; Bangdiwala, S.; Frauman, A.; Ganskey, S.; Bradley, C.: Effects of a school-based intervention to reduce cardiovascular disease risk factors in elementary school children:the cardiovascular health in children (CHIC) study. Journal of Paediatrics, 2004, 797-805.

10. Arbeit, M. L.; Serpas, D. C.; Johnson, C. C.; Forcier, J. E.; Berenson, G. S.: The implementation of a cardiovascular school health promotion program: utilization and impact of a school health advisory committee: the Heart Smart program. Health Educ Res, 1991, 6(4):423-430.

11. Tate, R. B.; Fernandez, N.; Yassi, A.; Canizares, M.; Spiegel, J.; Bonet, M.: Change in health risk perception following community intervention in Central Havana, Cuba. Health Promot Int, 2003, 18(4):279-286.

12. Bryant, T.: Role of knowledge in public health and health promotion policy change. Health Promot Int, 2002, 17(1):89-98.

13. Addison, C.; Campbell, B.: Teachers' assessment of the health status of students. The Urban Researcher, 2003, Winter: 40-46. 